\title{
Monte Carlo radiative transfer simulation to analyze the spec- tral index for remote detection of oil dispersed in the southern Baltic Sea seawater column: the role of water surface state
}

\author{
Otremba Zbigniew, ${ }^{1, *}$ Piskozub Jacek, ${ }^{2}$
}

\author{
Physics Department, Gdynia Maritime University, ul. Morska 81-87, 81-225 Gdynia, Poland \\ 2 Institute of Oceanology, Polish Academy of Sciences, ul. Powstańców Warszawy 55, 81-712 Sopot, Poland \\ * Correspondence: z.otremba@wm.umg.edu.pl
}

\begin{abstract}
The presented results of simulations take into account the optical parameters of the selected sea region (from literature data on the southern Baltic Sea) and two optically extreme types of crude oil (from historical data) which exist in the form of a highly diluted oil-in-water emulsion $(10 \mathrm{ppm})$. The spectral index was analyzed based on the results of modelling the radiance reflectance distribution for almost an entire hemisphere of the sky (zenith angle from 0 to $80^{\circ}$ ). The spectral index was selected and is universal for all optically different types of oil (wavelengths 650 and $412 \mathrm{~nm}$ ). The possibility of detecting pollution in the conditions of the wavy sea surface (as a result of wind of up to $10 \mathrm{~m} / \mathrm{s}$ ) was studied. It has been also shown that if the viewing direction is close to a direction perpendicular to the sea surface, observations aimed at determining the spectral index are less effective than observation under the zenith angle of incidence of sunlight for all azimuths excluding the direction of sunlight specular reflection.
\end{abstract}

Keywords: oil-in-water emulsion; seawater; oil pollution detection; radiance reflectance; Monte Carlo simulation, spectral index

\section{Introduction}

Oily substances may be under the surface of the water, both as a result of the influence of the environment and deliberate transfer of oil from the form of the floating layer on the surface of the water to the submerged form, which is justified in terms of ensuring easier access of oil-decomposing bacteria, but may also be dictated by a desire to hide illegal oil discharge. In any case, there is a need to conduct research on the efficiency of substances supporting the dispersion of oil [1] and research on the possibility of detecting oil contamination in the form of an emulsion $[2,3]$.

The use of aircraft, drones and satellites to remotely detect oil spills is possible over a wide range of electromagnetic waves (from ultraviolet to microwave) [4]. But when the oil remains in the water column, only the visible range of electromagnetic waves (VIS) can be used because ultraviolet (UV), infrared (IR) and microwave (MW) radiation is strongly absorbed by water [5]. The interaction of sunlight with water and its components, as well as with oil droplets of oil-in-water emulsion, is reflected in the spectral and directional distribution of the above-water radiance field. This effect was used to estimate the contrast between the sea area containing the dispersed oil and the area free of oil $[6,7]$. Research on the search for an appropriate spectral index has already been carried out involving the waters of the Gulf of Gdańsk (the Baltic Sea), which could potentially contain types of oil with extremely different optical parameters. The analyses concerned viewing directions perpendicular to the water surface [8] and various viewing angles in the plane of incidence of direct sunlight [9] were carried out. In our earlier paper [10], the effectiveness of the use of the spectral index was analyzed as a function of the viewing direction within almost all possible directions of observation. That paper shows the dependence of the spectral index on the thickness of the polluted sea layer for the waters of 
the southern Baltic Sea, taking into account the optical properties of crude oil extracted in this region. On the other hand, this paper supplements this information by showing the weakening of the spectral coefficient along with the increase in the degree of waving of the sea surface. In addition, this paper uses oils with extremely different optical properties.

\section{Materials and Methods}

In the radiative transfer simulation, the optical parameters of seawater in the southern Baltic region were applied (data published by Sagan [11] and further cited by Baszanowska et al. [9]). On the other hand, as a factor disturbing the natural light transfer, two types of crude oil were used, whose optical parameters are shown by Otremba [12], and as an oil-in-water emulsion form by Baszanowska et al. [9]. The optical properties used in the study (i.e. the absorption coefficient spectra and the scattering coefficient spectra) of the seawater and the oil-in-water emulsion that pollutes this water is shown in Figure 2. Differentiation of the spectra shapes for seawater in relation to oils is also visible in this picture. This encourages the search for the possibility of remote detection of oil pollution in the water column.

The absorption coefficient for Petrobaltic crude oil is low across the spectrum in contrast to Romashkino crude oil. Similarly, the refractive index for Petrobaltic has low values, but for Romashkino it has high values. Petrobaltic crude oil is extracted in the southern Baltic Sea, while Romashkino crude oil is extracted on land (Eastern Europe Romashkino Field, Russia). Other types of crude oil, lubricating oils and fuels have optical properties in the range between Petrobaltic and Romashkino [12]. A schematic representation of the optical model of the sea free of oil and contaminated with dispersed oil in Figure 2 is shown. In this model, the water surface is wavy, according to the Cox \& Munk statistics [13].
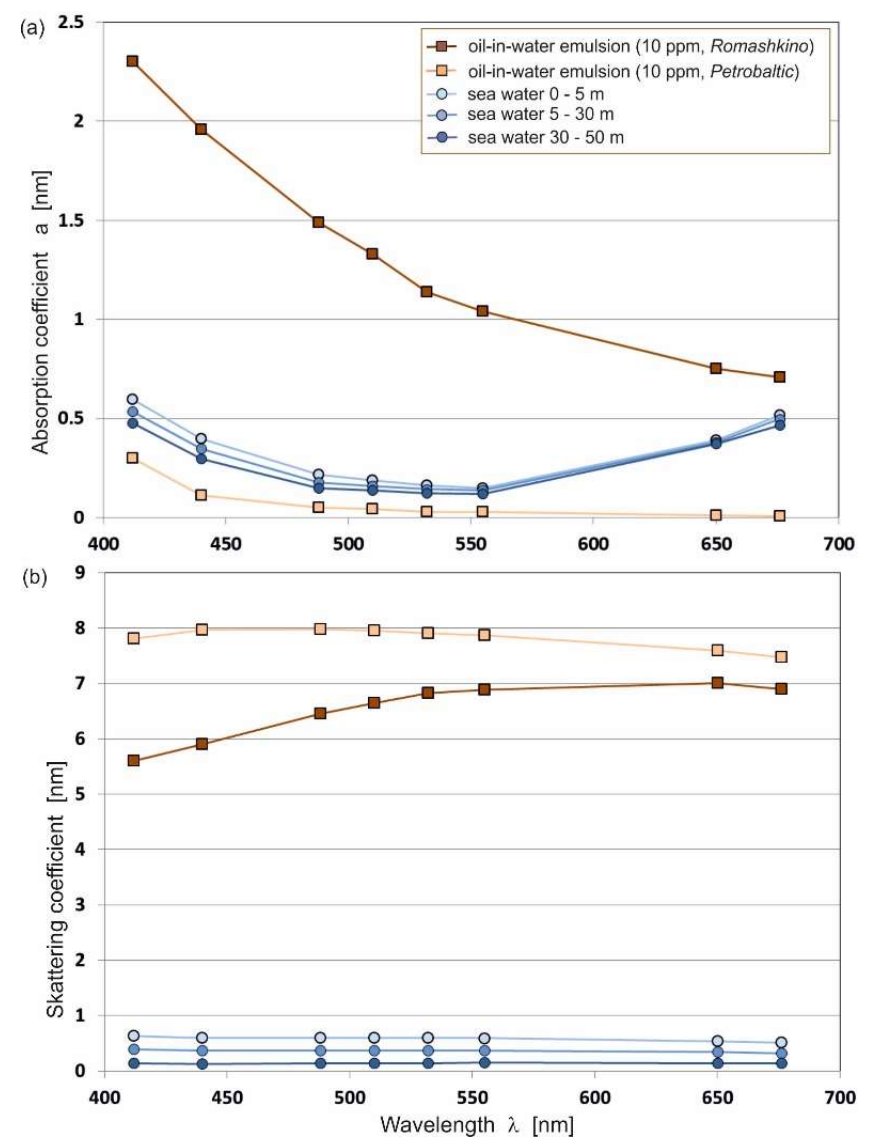
Figure 1. Spectra of both absorption coefficient (a) and scattering coefficient (b) of seawater and oil-in-water emulsions (10 ppm).

Water virtually polluted with oil in a concentration of $10 \mathrm{ppm}$ was analyzed in the simulation tests. The principle and course of the procedure aimed at obtaining the radiance distribution of light reflected from the sea are described by Baszanowska et al. [8,9]. In the study, it was assumed that the sky was cloudless. The optical model of such a sky took into account both direct photons from the sun and photons scattered in the atmosphere [7]. Virtual detectors were located above the water surface (atmospheric modification of the above-water radiance field was not taken into account).

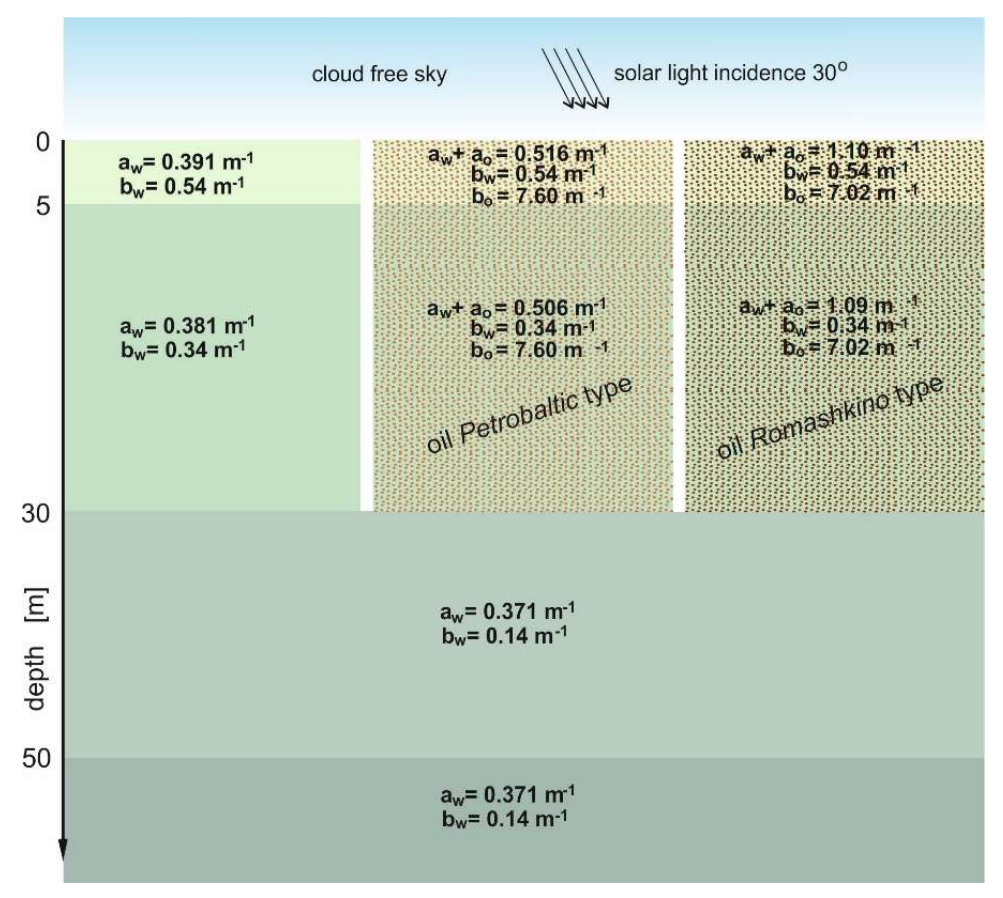

Figure 2. Optical model of sea basin for a sample wavelength $(655 \mathrm{~nm})$ applied for Monte Carlo simulations of radiative transfer.

\section{Results}

The initial product of individual simulations was the radiance reflectance $\left(R_{\mathrm{L}}\right)$ for 1,620 directions related to various zenith angles $(\theta)$ and azimuth angles $(\varphi)$. $R_{\mathrm{L}}$ is the ratio of the above-water upwelling radiance $\operatorname{Lu}(\theta, \varphi)$ in the viewing direction $\theta, \varphi$ to the above-water downwelling vector irradiance $E_{d}$. In the ocean, optics $R_{L}(\theta=0)$ is often called remote-sensing reflectance $\left(\mathrm{R}_{\mathrm{rs}}\right)$.

The spectral index $\mathrm{I}\left(\theta, \varphi, \lambda_{n}, \lambda_{\mathrm{m}}\right)$ was defined as the ratio of the radiance reflectance for the longer wavelengths to the remote sensing reflectance for the lower wavelengths for selected viewing direction $\theta, \varphi(1)$ :

$$
\mathrm{I}\left(\theta, \varphi, \lambda_{\mathrm{n}}, \lambda_{\mathrm{m}}\right)=\frac{\mathrm{L}_{\theta, \varphi}\left(\lambda_{\mathrm{n}}\right)}{\mathrm{L}_{\theta, \varphi}\left(\lambda_{\mathrm{m}}\right)}
$$

where: $\lambda_{n}, \lambda_{m}$ - higher wavelength and lower wavelength.

$\mathrm{I}\left(\theta=0, \lambda_{n}, \lambda_{\mathrm{m}}\right)$ values were determined for every possible combination of wavelengths (a total of 28 - shown in Figure 3). 


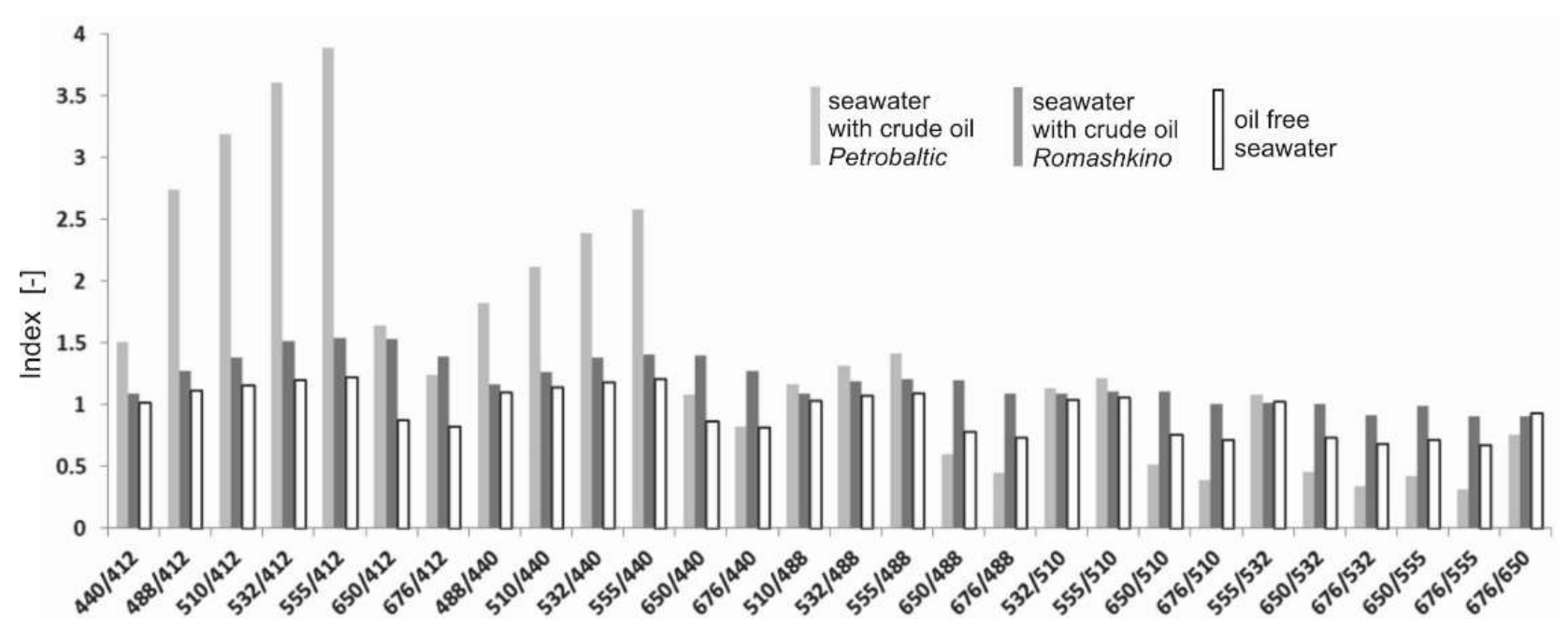

Figure 3. Spectral indices of the sea free of oil and in conditions of dispersed oil contamination for a wind-induced rough sea surface $(2 \mathrm{~m} / \mathrm{s})$.

By using this data, the differences between values of spectral indices of water polluted with dispersed oil and values of indices of oil-free water were determined for viewing angle $\theta=0^{\circ}$ (shown in Figure 4 ).
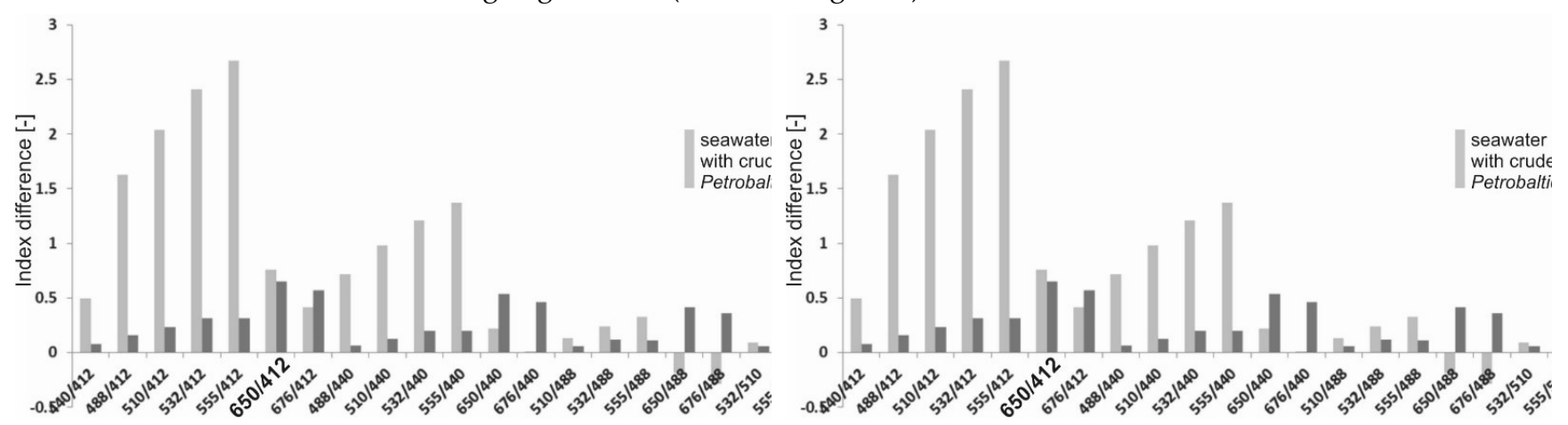

Figure 3. Differences between values of spectral indices of water contaminated by dispersed oil and values of indices of oil-free water contamination for a wind-induced rough sea surface $(2 \mathrm{~m} / \mathrm{s})$.

After analyzing the bar graph in Figure 4, the combination 650/412 was selected from all the wavelength combinations. This combination was found to be the most advantageous because, although these are high values, they are similar for various types of oil.

The difference indices were determined for each of the 1,620 directions of sea surface observation (zenith $\theta$ from 0 to $80^{\circ}$, azimuth $\varphi$ in full angle every $10^{\circ}$ ), both with the use of simulation results using optical parameters of Petrobaltic type oil (Figure 5) and Romashkino type oil (Figure 6). Figures 5 and 6 show the range of directions for which observation is ineffective, i.e. directions around the direction in which the light coming directly from the sun would be mirrored. Along with the increase in the degree of the sea surface heaving (after wind speed increase), the range of unfavorable oil detection directions becomes wider due to the solar light reflections from wave slopes.

The directions favorable for the detection of the dispersed oil appeared at zenith angles close to the zenith angle of direct sunlight (in Figures 5 and 6, these directions are revealed in yellow and white).

The tallest bar in Figure 4 falls on the differential index 555/412. It corresponds to the substance with the optical properties of Petrobaltic crude oil. At the same time, the differential index that corresponds to the Romashkino crude oil is relatively low for this 
wavelength combination. If it was possible to predict the possibility of spreading an oil emulsion whose droplets are a hydrocarbon mixture similar to Petrobaltic crude oil, index $555 / 412$ would clearly be the most advantageous.

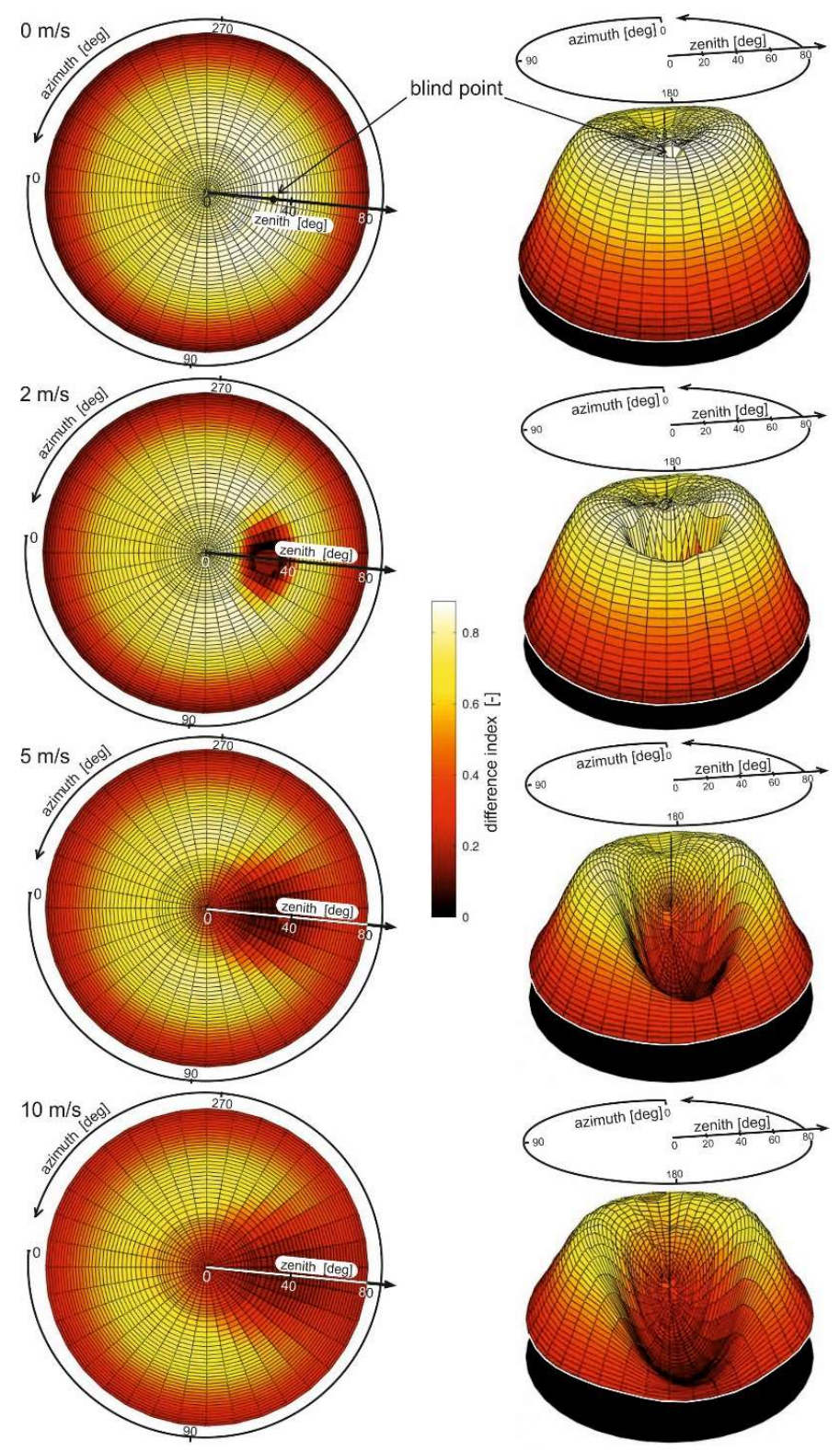

Figure 5. Difference index in cylindrical coordinates (left side- 2D maps, right side -3D contour maps) for the various wind-induced sea surface states (wind speed indicated upper left) from the Monte Carlo simulations for seawater polluted by Petrobaltic-type oil for a $10 \mathrm{ppm}$ oil concentration. 


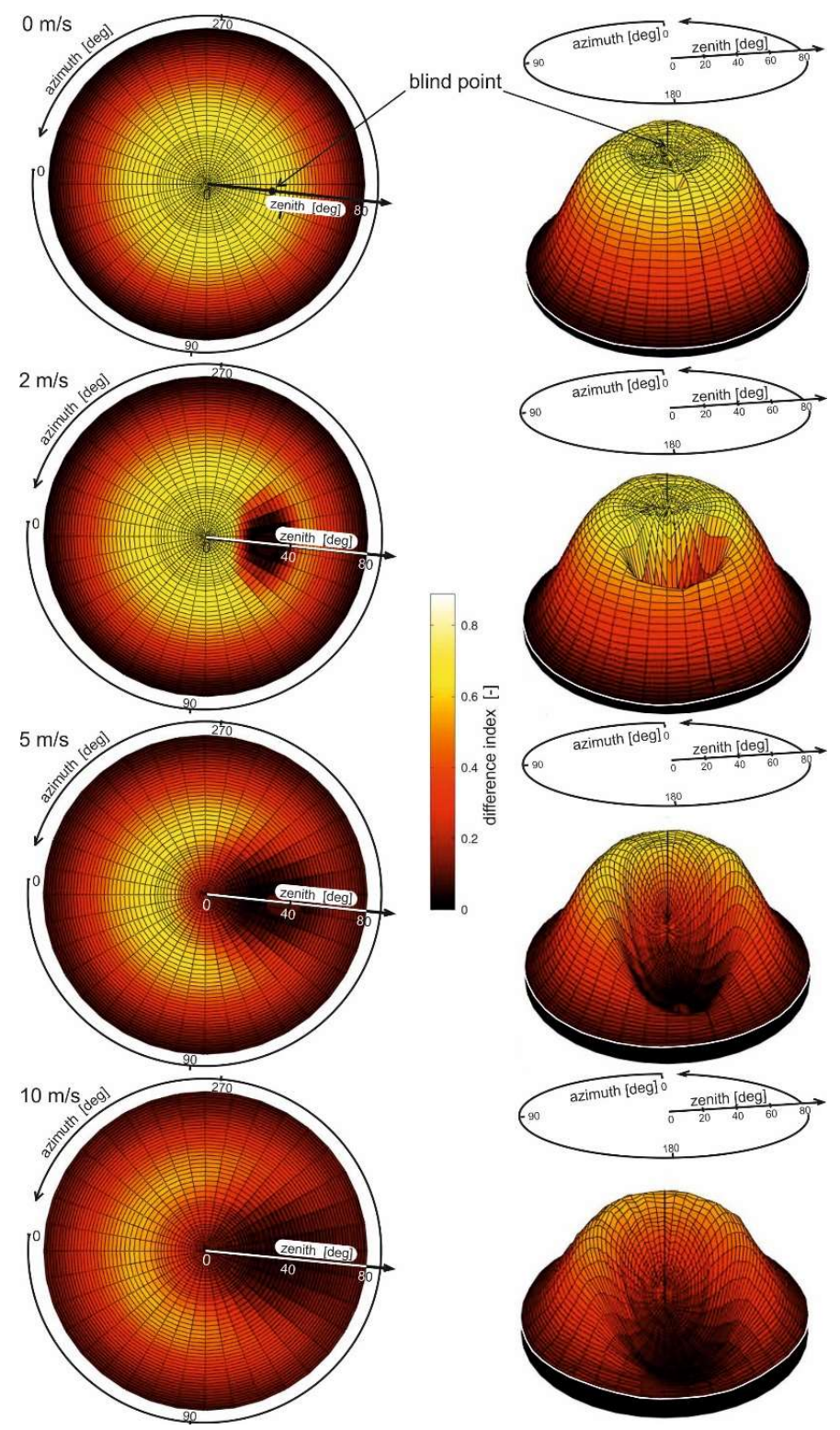

Figure 6. Difference index as in Figure 4, but for Romashkino type oil.

If the surface of the sea was smooth, the preferred direction of observation would be close to the direction of reflection of direct sunlight, excluding the specular reflection of the solar beam (which is visible in the upper right graph in Figures 5 and 6). It would be impossible to detect the oil dispersed in the water column if the observation took place at a large zenith angle (dark red and black in Figures 5 and 6).

\section{Conclusions}

Alien substances dispersed in the water column can manifest their presence above the sea surface in a spectral and directional distribution of bottom-up radiance. The findings reported in this paper suggest that a spectral index of 650/412 would be useful for the detection of an oil-in-water emulsion under cloudless sky conditions. This index is in outwardly contradiction with the index proposed in an earlier paper [10] (555/412), where it was assumed that it would only be used to detect oil extracted in the southern Baltic Sea. It is also confirmed that the orientation of the radiance detector is important. 
The viewing direction is optimal if it corresponds to the zenith angle of the sun, but in terms when the azimuth angle falls to direction close to perpendicular one to the plane of solar rays incidence. The source of credibility of the presented results lies in the optical properties of the oils, and more specifically in their spectral courses of the refractive index and the absorption coefficient. If the water column contained dispersed non-oil substances with optical properties from the range of properties assigned to oils (crude oil and petroleum derivatives), detection by measuring the spectral indicator could be false. However, the appearance of an increased value of the spectral index creates a situation that prompts the use of a chemical method to confirm the pollution of the sea with oil substances.

Author Contributions: Conceptualisation, Z.O. and J.P.; methodology, Z.O. and J.P.; formal analysis, Z.O.; investigation, Z.O.; data curation, Z.O.; software, J.P.; writing, Z.O. and J.P.; visualisation, Z.O. All authors have read and agreed to the published version of the manuscript.

Funding: This paper was founded by Gdynia Maritime University, grant no. WM/2021/PZ/01, and the Institute of Oceanology of Polish Academy of Sciences, statutory task I.3.

Institutional Review Board Statement: Not applicable

Informed Consent Statement: Not applicable

Conflicts of Interest: The authors declare no conflict of interest.

\section{References}

1. Merlin, F.; Zhu, Z.; Yang, M.; Chen, B.; Lee, K.; Boufade, M. C.; Isaacman, L.; Zhang, B. Dispersants as marine oil spill treating agents: a review on mesoscale tests and field trials. Environ Syst Res 2021, 10, 37, 2-19. https://doi.org/10.1186/s40068-021-00241-5.

2. Lai, Q.; Xie, Y..; C. Wang, C.; Wang, M.; Tan, J., Multiband directional reflectance properties of oil-in-water emulsion: application for identification of oil spill types. Appl. Opt. 2021, 60, 6902-6909. https://doi.org/10.1364/AO.427978.

3. Haule, K.; Toczek, H.; Borzycka K.; Darecki M. Influence of Dispersed Oil on the Remote Sensing Reflectance - Field Experiment in the Baltic Sea. Sensors, 2021, 21, 5733. https://doi.org/10.3390/s21175733

4. Fingas M. Oil Spill Science and Technology, 2nd ed. (Elsevier 2017).

5. Dera J.; Wozniak B. Light Absorption in Sea Water, 4th ed., Springer, 2007.

6. Otremba, Z.; Zielinski, O.; Hu, C. Optical contrast of oil dispersed in seawater under windy conditions, J. Eur. Opt. Soc. Rapid Publ., 2013, 8, 13051. https://doi.org/10.2971/jeos.2013.13051

7. Baszanowska, E.; Otremba, Z.; Piskozub, J. Modelling the Visibility of Baltic-Type Crude Oil Emulsion Dispersed in the Southern Baltic Sea, Remote Sens., 2021, 13(10), 1917, 2-18. https://doi.org/10.3390/rs13101917

8. Baszanowska, E.; Otremba, Z.; Piskozub, J. Modelling Remote Sensing Reflectance to Detect Dispersed Oil at Sea, Sensors, 2020, 20, 863, 1-11. doi: https://doi.org/10.3390/s20030863

9. Baszanowska, E.; Otremba, Z.; Piskozub, J. Modelling a Spectral Index to Detect Dispersed Oil in a Seawater Column Depending on the Viewing Angle: Gulf of Gdańsk Case Study, Sensors, 2020, 20(18), 5352, 1-11 (2020). https://doi.org/10.3390/s20185352

10. Otremba, Z.; Piskozub, J. Modelling the Spectral Index to Detect a Baltic-Type Crude Oil Emulsion Dispersed in the Southern Baltic Sea. Remote Sens., 2021, 13, 3927. https://doi.org/10.3390/rs13193927

11. Sagan, S. The inherent water optical properties of Baltic waters, Dissertations 21, Inst. of Oceanol., Sopot, Poland, 2008 (in Polish).

12. Otremba, Z. The impact on the reflectance in VIS of a type of crude oil film floating on the water surface, Opt. Express, 2000, 31, 129-134. https://doi.org/10.1364/OE.7.000129

13. Cox C.; Munk, W. H. Statistics of the sea surface derived from sun glitter, J. Mar. Res., 1954, 1054 13, $198-227$. 